1 Universidade Federal de São Paulo (Unifesp) - São Paulo (SP), Brasil.

franlacaz@hotmail.com

2 Universidade Estadual Paulista (Unesp) - São Paulo (SP), Brasil.

${ }^{3}$ Universidade Federal de São Paulo (Unifesp) Santos (SP), Brasil.

4 Universidade Municipal de São Caetano do Sul (USCS) - São Caetano do Sul (SP), Brasil.

\section{Movimento da Reforma Sanitária e Movimento Sindical da Saúde do Trabalhador: um desencontro indesejado}

\author{
Sanitary Reform Movement and Union Movement for Workers' \\ Health: an unwanted mismatch
}

Francisco Antonio de Castro Lacaz'1, Ademar Arthur Chioro dos Reis'1, Edvânia Ângela de Souza Lourenço ${ }^{2}$, Patrícia Martins Goulart ${ }^{3}$, Carla Andrea Trapé $\mathbf{4}$

DOI: 10.1590/0103-11042019S809

RESUMO O artigo discute a origem do Movimento da Reforma Sanitária Brasileira (MRSB) e do Movimento Sindical da Saúde do Trabalhador (MSST) e como a frágil base social da Reforma Sanitária tem relação com o ‘divórcio’ entre estes. Pauta-se na ótica da Saúde do Trabalhador a partir de revisão da literatura publicada na revista 'Saúde em Debate' e por autores nas décadas de 1980 a 2010 que compuseram a Comissão Nacional da Reforma Sanitária. Mostra o avanço obtido pelo MSST, nos anos 1970-1980, na implementação de Programas de Saúde do Trabalhador, protagonizados pelos sindicatos envolvidos na luta pela saúde no trabalho, assessorados por seu órgão intersindical, questão desconsiderada pelo MRSB. Com a hegemonia da reestruturação produtiva neoliberal global no País e o desemprego estrutural, há um declínio da ação do movimento sindical, enfraquecendo seu protagonismo na luta pela saúde no trabalho, o que poderia ter potencializado a luta pela Reforma Sanitária Brasileira.

PALAVRAS-CHAVE Reforma dos serviços de saúde. Sindicatos. Saúde do trabalhador. Sistema Único de Saúde.

ABSTRACT This article discusses the origin of the Brazilian Sanitary Reform Movement (MRSB) from the review of the literature published in the journal 'Saúde em Debate', by the National Commission on Sanitary Reform, from 1980 to 2010. (MSST), and how the fragile social base of the Health Reform is related to the 'divorce' between them. It shows the progress achieved by the MSST in the late 1970s and 1980s in the implementation of Worker's Health Programs, which were carried out by the Unions advised by their inter-union body, in the struggle for health at work, an issue which was disregarded by MRSB. With the hegemony of global neoliberal productive restructure in the country and structural unemployment, there is a decline in the action of the Union movement, weakening its role in the struggle for health at work, which could have potentiated the fight for Brazilian Sanitary Reform.

KEYWORDS Health care reform. Labor unions. Occupational health. Unified Health System. 


\section{Introdução}

Estudos sobre a trajetória da Reforma Sanitária Brasileira (RSB) apontam para sua fragilidade em função da ausência, ao longo do processo, da ampliação da base social, por priorizar uma atuação a partir do interior do Aparelho de Estado em uma perspectiva de 'quebra do Estado', configurando o que se caracterizou, conforme Oliveira ${ }^{\mathbf{1}}$, como Reforma Sanitária 'pelo alto'. Mais recentemente, Dantas² retoma essa abordagem com maior profundidade ao discutir o afastamento do Movimento da Reforma Sanitária Brasileira (MRSB) da perspectiva emancipatória de caráter socialista.

Cabe ressaltar também a quase ausência, durante seu desenrolar, da discussão do processo de acumulação de forças e de formulação teórico-prática encetado pelo Movimento Sindical Brasileiro (MSB) ${ }^{\mathbf{3} 4}$; o que Cohn ${ }^{\mathbf{5}}$, quando analisava, nos anos 1990, a literatura sobre o MRSB, considerou também uma deficiência já que

[...] ainda continua a imperar o desconhecimento desses atores sociais, [...] qualificados pelos marcos teóricos de nível macro de análise, e não por suas práticas concretas ${ }^{\mathbf{5 9 9}}$.

Acontece que, no final dos anos 1970, o MRSB, de maneira explícita, assume como campo de luta as relações trabalho e saúde ${ }^{6,7}$, conforme duas estratégias: articulando-se, internamente, suprapartidária e intersindicalmente e, externamente, em aliança com setores intelectuais médios, criando um organismo que desenvolve papel de verdadeiro intelectual orgânico'8, o Departamento Intersindical de Estudos e Pesquisas de Saúde e dos Ambientes de Trabalho (Diesat), projeto resgatado da experiência histórica do próprio MRSB, com o Departamento Intersindical de Estatística e Estudos Socioeconômicos (Dieese).

Mesmo sob ditadura empresarial-militar, o MRSB reivindicava saúde no trabalho, negociando com o empresariado sem a intervenção do Estado7 ${ }^{7}$. De modo autônomo, construía convenções e acordos coletivos de trabalho, mediante a negociação de cláusulas relativas à organização nos locais de trabalho visando ao controle da nocividade, e em defesa da saúde, ou criando assessorias técnicas sindicais para credenciar-se nos embates com o capital ${ }^{6,7}$. Com tais práticas, questionava a postura patronal manipuladora no que se refere às informações relativas às condições e ambientes de trabalho insalubres e sua repercussão na saúde dos trabalhadores, mediante avaliações públicas dessas condições/ambientes, tornando público aquilo que era privado ${ }^{4}$.

Ademais, a luta pela defesa da saúde no trabalho evolui para a criação de uma proposta de Política de Saúde do Trabalhador consubstanciada nos então chamados Programas de Saúde do Trabalhador (PST) por meio do desenvolvimento de ações programáticas voltadas à saúde dos trabalhadores na rede básica, ainda durante a vigência das Ações Integradas de Saúde, ou seja, antes da criação do Sistema Único de Saúde (SUS) e da municipalização da saúde ${ }^{9-11}$.

Uma destas experiências, O PST do Trabalhador Químico do ABCD, que funcionou de 1984 a 1988 nas cidades de Diadema, Mauá, Santo André, incorporou aspectos que se pode chamar de revolucionários. Eram eles: gestão compartilhada com Sindicato dos Trabalhadores Químicos do ABCD; horário de funcionamento das 17 horas às 21 horas; entrega do prontuário médico para o trabalhador; atuação do agente sindical de saúde que compunha a equipe de saúde e era capacitado para colher a história de trabalho de seus pares, sendo o primeiro contato do trabalhador quando adentrava aos centros de saúde, ligados à Secretaria de Estado da Saúde, para posterior consulta médica; não definição de tempo para duração da consulta médica. Posteriormente, o programa foi estendido para atender aos trabalhadores da construção civil de São Caetano do Sul12.

Aqui é pertinente apontar que o Grupo de Trabalho sobre Saúde do Trabalhador criado para assessorar a Comissão Nacional 
de Reforma Sanitária (CNRS) apontava esse avanço das experiências em serviço no campo Saúde do Trabalhador (ST) quando apresentou seu texto final submetido à Comissão ${ }^{\mathbf{1 3}, \mathbf{1 4}}$, a qual forneceu importantes subsídios políticos e técnicos para a instituição, mesmo retardatária de direitos sociais no Brasil, incluído o direito à saúde, inscrito pela primeira vez na Constituição Federal de 1988 (CF/1988) ${ }^{15}$.

Para além dos inegáveis efeitos positivos, sociais e políticos que a Carta Maior representou, ao mesmo tempo, foram sendo criados obstáculos para a efetivação daqueles direitos. Frise-se que, do ponto de vista sócio-econômico-político, a CF/1988 foi sendo desfigurada já a partir do início dos anos 1990, quando passa a configurar-se o projeto de Estado, calcado no neoliberalismo, projeto de poder político-ideológico ${ }^{16}$ que acabou por inverter o significado real das conquistas, ou seja, o Brasil teve, enfim, uma Constituição avançada socialmente, mas, na realidade, sua concretização esbarrou na reestruturação do papel do Estado, de cunho neoliberal ${ }^{17}$.

Ademais, com efeito pós-CF/1988, o acesso aos direitos ocorre de forma fragmentada. Assim, desde meados de 1990, a gestão de serviços públicos é repassada para 'entidades parceiras', na perspectiva da privatização do espaço público ${ }^{\mathbf{1 8}}$. Dessa forma, as políticas sociais foram transformadas em um nicho de mercado, pois deixam de ser papel do Estado, passando a sê-lo de entidades privadas, mediante repasse de recursos financeiros públicos, sem assumir as responsabilidades ou normas da administração pública ${ }^{19}$.

Não obstante, em âmbito nacional e internacional, debate-se acerca do real papel do Estado a partir da crise econômica de 2008; e, em resposta, medidas vêm sendo tomadas para superar barreiras das taxas de acumulação e, ao mesmo tempo, ampliar a dominância do Capital em âmbito mundial. Essas medidas estão alinhadas ao aprofundamento da exploração do trabalho e da retirada de direitos, impactando profundamente a vida social ${ }^{20}$.
Tendo como referência o olhar do campo $\mathrm{ST}^{7}$ - e considerando a origem contemporânea do MRSB e do MSST - objetiva-se, no presente artigo, discutir se o que foi entendido como a estreita base social da Reforma Sanitária ${ }^{\mathbf{1 , 2}}$ poderia ter sido superada e enfrentada com uma maior aproximação entre ambos os movimentos, em uma espécie de sinergia político-programática.

\section{Aspectos metodológicos}

Ao buscar discutir pelo olhar da ST a Reforma Sanitária, partimos da análise bibliográfica e documental, com especial atenção na fragilidade da base social da Reforma Sanitária.

Considerando-se a problemática acima discutida, e o fato de que o MRSB tem como marco institucional a criação do Centro Brasileiro de Estudos de Saúde (Cebes), consultou-se a coletânea da revista 'Saúde em Debate', no período de 1976 a 1998, identificando os números $3^{21}, 9^{22}, 11^{23}$ e $12^{24}$ que trataram da temática ST. Registre-se que, em 1976, foi publicado o primeiro número do periódico, mas foi somente no número 11, em 1981, que se detecta uma maior aproximação com a temática trabalho e saúde, mediante ampla pauta a ela dedicada, inclusive com um artigo de Laurell25, uma das principais pesquisadoras sobre as relações trabalho-saúde em uma perspectiva progressista e que teve grande influência no Brasil.

A essa 'garimpagem', somou-se consulta aos documentos elaborados pela Comissão Nacional da Reforma Sanitária ${ }^{\mathbf{1 3}, \mathbf{1 4}}$, além de artigos, livros ${ }^{26}$ e capítulos de livros, especialmente do livro que relata a história da Reforma Sanitária ${ }^{27}$.

Além disso, foram consultadas publicações produzidas pelo Diesat ${ }^{\mathbf{3}, 4}$, bem como relatório de pesquisa na qual foram analisados aspectos importantes da experiência do PST do $\mathrm{ABCD}^{12}$, já referido, ao que se aliou o resgate de livros de autores fundamentais da Reforma Sanitária26,27 e do Modelo Operário Italiano7. 


\section{A origem comum e a deficiente base social da Reforma Sanitária}

Quanto à origem da RSB, estudiosos têm apontado o importante papel desempenhado pela Academia, nos anos 1970-80, particularmente a partir de formulações teórico-metodológicas desenvolvidas pelos Departamentos de Medicina Preventiva e Social (DMPS) ${ }^{\mathbf{2 8}}$ que funcionaram como polos irradiadores de propostas sobre a reforma do sistema nacional de saúde ${ }^{29}$; pela criação do Cebes (e da revista 'Saúde em Debate') e pela fundação da Associação Brasileira de Pós-Graduação em Saúde Coletiva (Abrasco) em 1979.

Ademais, é assinalada a capacidade dos atores do MRSB em atuar na conjuntura do final da década de 1970, marcada pela luta da anistia, pela redemocratização e denúncia dos impactos da política econômica e social sobre a saúde e as condições de vida das classes trabalhadoras, buscando, em particular, propor 'soluções inovadoras' que, dentro ou fora das universidades, propiciaram a criação, conforme assinala Teixeira ${ }^{29}$

[...] de centros de pesquisa em saúde coletiva [...] de uma entidade nacional, como o Centro Brasileiro de Estudos de Saúde [...] a publicação de uma revista 'Saúde em Debate' e de vários livros, as inúmeras conferências e debates respondiam às necessidades de difusão ideológica(198).

De acordo com Sato, Lacaz e Bernardo30 e Tambellini ${ }^{31}$, percurso semelhante cursou o MSST, que, em um momento contemporâneo ao do surgimento do Cebes, criou a Comissão Intersindical de Saúde do Trabalhador (Cisat), em 1978, a qual passou a promover, desde 1979, as Semanas de Saúde do Trabalhador (Semsat) ${ }^{\mathbf{3}, 32}$, além de criar a revista Trabalho \& Saúde ${ }^{3,6,7}$.

Ao lado disso, o MSST promoveu intenso debate mediante fóruns, seminários e encontros que visaram desmascarar e denunciar a política de higiene e segurança do trabalho adotada pelo Estado, por meio do Ministério do Trabalho, a qual, segundo propaganda oficial, teria levado à melhoria das condições de trabalho, expressa na queda dos acidentes de trabalho no País, a partir de meados/final dos $1970^{3}$, época das grandes greves em todo território nacional, muitas delas de notório caráter político-contestador ${ }^{4}$.

Para corroborar o divórcio das questões relacionadas com a saúde no trabalho, durante a Constituinte, assim coloca-se Fleury:

E aí eu identifico no deputado Eduardo Jorge [PT] a tentativa de colocar mais claramente na constituição federal os direitos em relação à saúde do trabalhador, dos quais não entrou quase nada $[\ldots . .]^{27(233)}$.

Aceitando o que é apontado como o principal aspecto criticável do MRSB, ou seja, sua estreita base social ${ }^{2,26,28}$, cabe perguntar: tal realidade seria explicada pela trajetória e origem assumidas pelo MRSB?

Essa é uma possível explicação, na medida em que poderia ter como importante aliado o MSST em sua luta pela defesa da incorporação de ações em $\mathrm{ST}^{\mathbf{8}}$ na rede pública ${ }^{9}$, contemporânea ao MRSB e também voltada para a luta pela implantação de um Sistema Nacional de Saúde ${ }^{33,34}$.

Tal aliança seria benéfica, mesmo considerando-se a diferença quanto ao objetivo imediato buscado, ou seja, a principal proposição do MSST seria compartilhada com um ator social que, pelo menos no discurso, também era privilegiado pelo MRSB um "[...] aliado potencial: o trabalhador adoecido no processo de produção"29(198), conforme o discurso do MRSB na busca de aliados na sociedade civil.

Ocorre que a categoria trabalho era (e ainda é) desconsiderada enquanto determinante para o desenvolvimento de doenças, embora as estatísticas recém-criadas pela estatização do seguro acidente de trabalho a denunciasse ${ }^{\mathbf{8}, \mathbf{9}}$.

Ademais, aquela trajetória e origem comum também eram sustentadas, segundo Mendes ${ }^{35}$, 
pelas formulações teórico-metodológicas, acrescida da formação de quadros provenientes dos DMPS, o que já havia sido assinalado por Tambellini ${ }^{\mathbf{3 1}}$, ao considerá-los espaços privilegiados de produção das principais contribuições do estudo das relações saúde-trabalho e processo saúde/doença.

As formulações das 'medicinas preventivas'28,31, subsidiaram a incorporação pela rede pública de saúde das ações programáticas em ST, as quais foram 'interlocutoras' do movimento sindical ${ }^{9} \mathrm{em}$ sua aproximação com as questões relativas à saúde-trabalho, ao caminhar rumo ao rompimento com o assistencialismo médico sindical, teimosa herança do Estado Novo getulista ${ }^{8}$.

Tal transformação ocorre a partir do início dos 1980, o que também passou desapercebido pelos teóricos do MRSB. Tal fato é intrigante por si só, particularmente quando se constata que o Movimento Sindical assumiu a defesa de um modelo não privatista e de boa qualidade como bandeira - especialmente categorias como químicos, bancários e metalúrgicos ${ }^{3}-$, apesar de continuarem garantindo, contraditoriamente, nos acordos coletivos firmados com os empresários "[...] a assistência médica supletiva, oferecida pelo setor privado e principalmente pelas empresas de medicina de grupo"36(10).

Nessa 'aproximação' com a saúde pública ${ }^{37}$, o MSST atuou politicamente denunciando serviços médicos de empresa caracterizados pela baixa cobertura e cujas práticas antiéticas, visando rígido controle da força de trabalho ${ }^{38}$, foram desnudadas pela ação/denúncia dos $\mathrm{PST}^{\mathbf{8}}$.

Existem claros exemplos de enfrentamento por parte dos sindicatos de trabalhadores, que passaram a atuar na gestão dos PST, amplamente relatados em livro publicado em 1989 resultante de pesquisas empreendidas pelo Diesat por demanda dos sindicatos filiados 4 .

Assim, parece não ter sido apenas a origem acadêmica o elemento único a influenciar a base social das experiências dos PST, quando tiveram como razão de sua existência o movimento social dos trabalhadores e por terem surgido no bojo da mesma conjuntura política em que se originou o MRSB.

$\mathrm{Na}$ época, vicejam as formulações teórico-metodológicas da saúde coletiva que recuperaram a categoria trabalho na determinação do processo saúde-doença. Apontavam o papel determinante do trabalho, indicaram-no como espaço concreto de exploração e deram relevo à defesa da saúde no trabalho operário como expressão concreta dessa exploração ${ }^{7,38}$.

Concomitantemente, sindicatos em várias partes do mundo inscrevem a saúde como uma de suas pautas de reivindicação, passando a questionar o modelo da medicina do trabalho, centrado no saber médico, o que subsidiará estudos sobre saúde dos trabalhadores 7,36.

Também é preciso considerar as práticas em ST, expressas hoje na ação dos Centros de Referência em Saúde do Trabalhador (Cerest), englobados na Rede Nacional de Atenção Integral à Saúde do Trabalhador (Renast) ${ }^{39}$, como parte da Política Nacional de Saúde e Segurança no Trabalho ${ }^{40}$ e da Política Nacional de Saúde do Trabalhador e da Trabalhadora ${ }^{\mathbf{4 1}}$, propostas pelo Ministério da Saúde, temas caros ao MSST.

Trata-se da introdução de novas formas de organização e gestão do trabalho em saúde, procurando romper com a hegemonia médica, ao enfatizar a atuação em equipe e a educação em saúde como elemento de busca da 'consciência sanitária'42.

Paralelamente, prioriza a troca de saberes entre: 'coletivo-médico-sanitário’ e ‘clientela-usuária/trabalhadora-cidadã', apreendida pelo serviço mediante sua inserção social na produção, não pelo consumo, como é costumeiro nos serviços de saúde, ao lado de coletivizar as experiências particulares, dinamizando as tarefas das equipes de saúde ${ }^{43}$, aliando o atendimento individual à intervenção sobre os ambientes de trabalho pelas ações de vigilância em ST ${ }^{8,9}$ de caráter multiprofissional e dando consequência preventiva às informações colhidas no momento da história profissional.

Essa prática evidencia elemento importante salientado no 'revisionismo' sobre o 
MRSB, conforme Fleury ${ }^{\mathbf{4}}$, prócer da Reforma Sanitária, corroborando nossa avaliação:

[...] ao não questionar o modelo médico de atenção à saúde, o projeto reformador acaba por perder o seu conteúdo de radicalidade democrática, de desalienação, para enquadrar-se como razão administrativa que, destematizando a potencialidade política e conflitiva deste processo, acaba por acarretar a passividade consumista dos 'cidadãos'44(10).

Assim, é necessário pautar a reflexão sobre o modelo assistencial já que, entendemos, seu não questionamento relaciona-se com o esgotamento do MRSB, como já apontaram Oliveira ${ }^{1}$, Cohn ${ }^{\mathbf{5}}$, Fleury ${ }^{\mathbf{4 4}, 45}$, Lacaz $^{\mathbf{3 3}}$ e Dantas ${ }^{2}$.

Frise-se que, na conjuntura analisada, a influência da Reforma Sanitária Italiana (RSI) ${ }^{\mathbf{4}}$ é marcante no Brasil, tanto como espelho para a RSB como referência para a luta do MSST, o qual espelhava-se na trajetória do Movimento Operário Italiano, que foi amplamente divulgado e compartilhado entre nós ${ }^{22,46}$.

Tal lembrança remete à necessidade de a RSB precisar construir uma base social de apoio, como ocorreu na RSI, cujas características mais importantes foram: ter contado com uma ampla base social, coroando processo de acumulação de forças hegemonizado por partidos políticos de esquerda, tendo à frente o extinto Partido Comunista Italiano que traçou como seu eixo condutor principal a luta pela saúde nas fábricas, através do controle da nocividade do trabalho visando superação da 'monetização do risco', conforme acontecia no período fascista e no imediato pós-guerra dentro da lógica capitalista de relações capital-trabalho ${ }^{\mathbf{4 2}, 46}$.

Por isso, causa espanto como foi muito pouco estudada, na análise da fragilidade da RSB, a luta empreendida pelo MSB na consolidação de um projeto que dura quase 40 anos ${ }^{11}$. É algo de estranhar já que, saliente-se, foi originado contemporaneamente ao MRSB, tendo durante algum tempo contado com o envolvimento de intelectuais engajados no trabalho de consolidação da proposta do Cebes, organismo este que ocupou de forma destacada espaço privilegiado de articulação da sociedade civil no debate e discussão dos pressupostos da nossa Reforma Sanitária ${ }^{26,44,45}$.

Cabe-nos, aqui, realçar essa lacuna observada nos estudos sobre a RSB e levantar questões que contribuam para iluminar o caminho trilhado pelo movimento sindical desde 1978 quando, ao engendrar aliança política com intelectuais oriundos do movimento sanitário, traçou a estratégia de se aparelhar para a luta pela saúde nos locais de trabalho ${ }^{7}$, criou a Cisat ${ }^{3}$. Outrossim, como já apontamos anteriormente, passou a realizar e protagonizar encontros, debates, seminários e as Semsats, marcos históricos da articulação entre o movimento sindical e setores médios representados por intelectuais, técnicos e acadêmicos.

Entendemos que, de certa forma, tal estratégia mimetiza o papel desempenhado pelo bloco de partidos de esquerda por ocasião da RSI ${ }^{46-48}$ colocando na cena política, bem como nas páginas dos principais jornais da grande imprensa, para o conhecimento da opinião pública, ainda durante os 'anos de chumbo', a discussão das reais condições de exploração do trabalho durante o regime militar, o 'milagre brasileiro' e seus reflexos sobre a vida e a saúde das classes trabalhadoras ${ }^{\mathbf{3} 49}$.

Diante disso, cabe indagar: por que a luta contemporânea pela saúde no trabalho ficou 'esquecida' nas análises sobre a RSB? Ainda mais sabendo-se que o movimento empreendido pelos sindicatos de trabalhadores inspirava-se claramente na experiência italiana, instigado pelo relato do livro 'Medicina e Política'42 de grande influência sobre intelectuais e sindicalistas engajados naquele projeto.

Frise-se que, como resultado dessa influência, o Brasil firmou convênio com a Itália, nos anos 1980, pelo qual médicos brasileiros participaram de intercâmbio para conhecer a experiência italiana. Maeno e Carmo ${ }^{50}$ explicitam que, por meio do convênio Brasil-Itália, "[...] dezesseis médicos brasileiros receberam 
bolsas de institutos italianos dedicados exclusivamente à Saúde do Trabalhador"(63).

Por outro lado, como elemento complicador, afirmamos que o SUS não incorporou em suas práticas na atenção básica a relação trabalho-saúde/doença, pois, com seu foco sobre a família, nem mesmo o trabalho domiciliar é objeto de sua ação, a ponto de ser pertinente questionar se é possível um diálogo entre ações em ST e a Estratégia Saúde da Família ${ }^{51}$, já que há um evidente descolamento entre o ideal de funcionamento da Política de Atenção Básica considerando o mundo real das equipes de saúde e produção do cuidado ${ }^{\mathbf{5 2}}$.

Uma das explicações para aquele 'esquecimento' pode ser buscada na observação - ao comentar a estratégia reformista -, de Fleury44(10):

Ao remeter a questão do poder ao nível do Estado, da sua institucionalidade legal e burocrática, acabou-se esquecendo que sua origem está na sociedade, na correlação de forças que fundamenta e reproduz o pacto de dominação.

Nesse sentido, os PST configuraram um modelo de relação dialética entre a reprodução social e a produção já que articularam assistência e vigilância, buscando romper com uma limitação 'cultural-estrutural' do setor saúde que é o seu alheamento do mundo do trabalho e da produção, ao não transpor os muros da fábrica, em uma perspectiva de tornar público o que é privado7. Tal prática contribuiu, inclusive, para uma mudança no padrão das estatísticas de doenças do trabalho em São Paulo e mesmo do perfil epidemiológico das doenças relacionadas com o trabalho $0^{4,53,54}$.

Parece-nos cada vez mais claro que não se pode abstrair desses aspectos em qualquer avaliação que se pretenda fazer das relações entre Reforma Sanitária e movimentos sociais quanto ao seu potencial de 'alavancar' o acesso a direitos como a saúde, já que, em um processo de transição democrática e de possibilidade de superação do atual bloco de poder, é
[...] bastante improvável que o avanço da cidadania tenha ocorrido sem que a classe trabalhadora trouxesse para seu campo de ideias a compreensão de questões tópicas ou 'técnicas' ligadas [...] às leis de proteção ao trabalho $[\ldots .] .55(62)$.

O que aconteceu, por exemplo, na luta dos trabalhadores italianos pela saúde no trabalho, a qual trouxe uma apreensão totalmente renovadora da relação entre leis sociais, trabalho, ambiente e saúde $\mathbf{4 7 , 4 8}^{\mathbf{4 8}}$.

No Brasil, começou a ter expressão quando da estratégia desenvolvida pelas entidades de assessoria intersindical, como o Diesat, e de sindicatos, na medida em que passaram a valorizar e associar a luta pela saúde no trabalho ${ }^{7}$ com a luta por condições e ambientes de trabalho também salubres ${ }^{4,53,56,57}$

Salientamos que tal temática foi pouco explorada nas publicações sobre RSB, particularmente quando se constata a relativa abundância de estudos sobre a importância dos Movimentos Populares de Saúde (Mops) na pressão por conquistas no campo da saúde pública, e se considera sua fragilidade estrutural ${ }^{58,59}$.

\section{Considerações finais}

Com o que foi anteriormente assinalado, buscamos apontar que existe um divórcio entre o caminhar do MRSB e o do MSST, veio riquíssimo de estudos ainda a ser mais explorado.

Não se pode afirmar que a 'teoria' da Reforma Sanitária negue o papel do movimento sindical na luta pela saúde no trabalho, mas a pequena ênfase temática dada a ela nos estudos mais importantes já referidos coloca esse desafio à nossa frente e permite refletir sobre os atores sociais que são necessários ter como parceiros na superação dos limites dados ao projeto do MRSB.

Para nós, o projeto de Reforma 'pelo alto' desconsiderou a relevância política da atuação sindical pela saúde no trabalho, já que ela existe 
e se expressou no avanço das cláusulas dos contratos de trabalho, no intersindicalismo do Diesat, nas assessorias técnicas intrassindicais e nas experiências de participação gestora dos PST/Cerest, muitas vezes complexa e conflitiva, como forma de interlocução com o saber instituído e o Aparelho de Estado ${ }^{8,57}$.

Tais experiências abriram a possibilidade de ousar reverter o modelo médico centrado mediante gestão/controle social da atuação técnica, diferentemente do estímulo ao consumo medicalizante exigido pelas massas/ maiorias silenciosas ${ }^{60}$.

As experiências programáticas e a formulação teórico-metodológica do campo $\mathrm{ST}^{61}$ que lhe dá sustentação vis-à-vis a abordagem hegemônica da medicina do trabalho-saúde ocupacional permitiriam pensar na possibilidade de seu desdobramento como um dos pilares da Reforma Sanitária em algumas regiões brasileiras, como o estado de São Paulo, o que, dialeticamente, também envolve suas dificuldades estruturais, na perspectiva de se vislumbrar a continuidade do avanço da ação sindical em saúde no trabalho entre nós.

Tal assertiva é particularmente importante considerando-se nos dias que correm a ausência de propostas orgânicas mais acabadas das Centrais Sindicais e dos partidos políticos de esquerda que configurassem um 'programa mínimo' para a área neste 'bloco histórico', superando a reforma 'pelo alto'.

Salientamos, mais uma vez, que essa questão está a comportar análises e estudos mais específicos, os quais, uma vez desenvolvidos, viriam a preencher uma lacuna importante que poderia contribuir para retomar uma maior interlocução entre MRSB e MSST ou outros movimentos sociais pela saúde.

Toda a formulação ora desenvolvida e sua potencial contribuição para pensar em uma retomada do MRSB esbarra, hoje, na fragilidade do movimento sindical e nas grandes transformações do mundo do trabalho aprofundadas a partir do final da década de 1980, com a reestruturação produtiva, a relocalização das fábricas, a automação e o aumento do chamado desemprego estrutural ${ }^{20}$.

Ao lado de tecer considerações ora indicadas, cabe problematizar os desafios contemporâneos para pensar a efetividade dos ideais da Reforma Sanitária e a defesa do direito à saúde, incluindo a especificidade do trabalho, em tempos de agudização da contradição Capital e Trabalho no atual estágio do capitalismo altamente informatizado, informalizado (sem regras), rentista e globalizado ${ }^{\mathbf{2 0 , 6 2}}$.

A isso, soma-se, quanto à defesa das políticas públicas, a ausência de reflexões e propostas orgânicas dos 'setores populares' que advoguem posições e linhas de condução política claras e nitidamente definidas, mesmo que conflitantes, dentro do espaço de debate político sobre a consolidação do SUS. Além disso, como elemento para aprofundar a discussão dos entraves e dificuldades identificados ao nível dos órgãos de Estado que atuam no campo da saúde e do trabalho, é mister considerar que alguns deles foram extintos pelo atual governo, como o Ministério do Trabalho e o da Previdência Social, sem que houvesse efetiva mobilização sindical para barrar tais iniciativas.

Tal preocupação torna-se especialmente importante e verdadeira ao se tomar conhecimento das propostas de reformas conservadoras de cunho neoliberal, como o Novo Regime Fiscal, instituído pela Emenda Constitucional 95/2017, que congela os gastos com políticas públicas por $20 \operatorname{anos}^{63}$, a já aprovada (contra) Reforma Trabalhista ${ }^{63} \mathrm{e}$ outras, hoje em curso, que levarão a sérias mudanças nos direitos constitucionais como os da previdência social ${ }^{64}$.

A isso, soma-se a forma de condução do processo de descentralização da saúde, que atribuiu aos estados e, em particular, aos municípios a responsabilidade pela implantação e operacionalização das políticas e ações de saúde sem o aporte de recursos necessários, fruto de um subfinanciamento histórico do SUS convertido, a partir do golpe de 2016, em desfinanciamento das ações e serviços de saúde 65,66 . 
Destaque-se, ainda, que se vive uma realidade em que além de não estar garantida a existência do modelo calcado nos serviços públicos, ora substituídos pela Organizações Sociais e outras modalidades de gestão indireta, subsiste uma brutal crise fiscal que há anos engessa a atuação do Estado brasileiro, o que projeta a privatização/terceirização da rede pública de saúde como a 'saída' para a superação crônica de sua deficiência financeira e técnico-administrativa ${ }^{19}$.

Mais ainda, a participação do movimento social nas instâncias de controle social do SUS, em que ocorre, tende a se dar, muitas vezes, por indicação de sindicatos de trabalhadores ou federações/centrais que reivindicam, na maioria das vezes, demandas pontuais sobre problemas ocorridos no processo de trabalho, de caráter fiscalizador, ou médico-assistencial.

Por outro lado, como uma teimosa contradição, os sindicatos continuam a priorizar a negociação e os convênios e planos de saúde aos seus associados ${ }^{67}$. Tal tendência aponta para a necessidade de reestabelecer uma articulação mais ampla na sociedade civil organizada, na medida em que a perspectiva é buscar arregimentar forças sociais visando elaborar propostas relativas a uma Política de Saúde que defenda e garanta o resgate da existência do SUS em seu todo, incluindo aquela relacionada com a $\mathrm{ST}^{\mathbf{1 1}}$.

Para nós, defensores de propostas emancipatórias, trata-se, então, de encetar uma luta anticapitalista, para além da democracia liberal e as pretensas propostas de superação de sua débâcle ${ }^{62}$.

\section{Colaboradores}

Lacaz FAC (0000-0001-7621-3756)* contribuiu para a proposição e definição do tema, escrita e revisão final do manuscrito. Reis AAC (0000-0001-7184-2342)*, Lourenço EAS (0000-0002-8997-7592)*, Goulart PM (00000002-5080-9241)* e Trapé CA (0000-00023272-6565)* contribuíram igualmente para a escrita e revisão final do manuscrito. 


\section{Referências}

1. Oliveira JA. Reformas e reformismos: para uma teoria política da reforma sanitária (ou, reflexões sobre a reforma sanitária de uma perspectiva popular). In: Costa NR, Minayo MCS, Ramos CL, et al, organizadores. Demandas Populares: políticas públicas e saúde. Petrópolis: Vozes; Rio de Janeiro: Abrasco; 1989. p. $13-44$.

2. Dantas AV. Do Socialismo à Democracia: tática e estratégia na Reforma Sanitária Brasileira. Rio de Janeiro: Fiocruz; 2017.

3. Ribeiro HP, Lacaz FAC, organizadores. De que adoecem e morrem os trabalhadores. São Paulo: Imesp; Diesat; 1985.

4. Departamento Intersindical de Estudos e Pesquisas de Saúde e dos Ambientes de Trabalho. Insalubridade: morte lenta no trabalho. São Paulo: Diesat-Oboré Editorial;1989.

5. Cohn A. Conhecimento e prática em saúde coletiva: o desafio permanente. Saúde soc. 1992; 1(2):97-109.

6. Lacaz FAC. Saúde no trabalho. São Paulo. [dissertação]. São Paulo: Faculdade de Medicina da Universidade de São Paulo; 1984.

7. Lacaz FAC. Saúde do Trabalhador: um estudo sobre as formações discursivas da academia, dos serviços e do movimento sindical. Campinas. [tese]. Campinas: Faculdade de Ciências Médicas, Universidade Estadual de Campinas; 1996. 456 p.

8. Gramsci A. Os intelectuais e a organização da cultura. São Paulo: Civilização Brasileira; 1968.

9. Freitas CU, Lacaz FAC, Rocha CE. Saúde Pública e ações de saúde do trabalhador: uma análise conceitual e perspectivas de operacionalização programática na rede básica da Secretaria de Estado da Saúde. Temas Imesc. Soc Dir Saúde. 1985; 2(1):3-10.

10. Lacaz FAC. Saúde do Trabalhador: vinte anos de história e trajetória. In: Brasil. Ministério da Saúde. $3^{\text {a }}$
Conferência Nacional de Saúde do Trabalhador: Trabalhar Sim! Adoecer, Não! Brasília, DF: Ministério da Saúde; 2005. p. 144-155.

11. Lacaz FAC, Vechia PRL, Silva VP. Gestão do trabalho em saúde: buscando a construção de uma Política de Saúde do Trabalhador da Saúde no âmbito municipal. In: Lacaz FAC, Goulart PM, Junqueira V, organizadores. Trabalhar no SUS: gestão, repercussões psicossociais e política de proteção à saúde. São Paulo: Hucitec; 2017. p. 330-367.

12. Botelho ZGA. Avaliação qualitativa de alguns aspectos organizacionais do programa de atenção ao adulto: projeto de atenção à saúde do trabalhador químico do ABC em duas unidades básicas. Relatório de Pesquisa. São Paulo: Instituto de Saúde da Secretaria de Estado da Saúde; Brasília, DF: CNPq; 1987.

13. Comissão Nacional da Reforma Sanitária. Grupo de Trabalho sobre Saúde do Trabalhador. Texto Final sobre Saúde do trabalhador. Documento 1. Brasília, DF: Comissão Nacional da Reforma Sanitária; 1986.

14. Comissão Nacional da Reforma Sanitária. Grupo de Trabalho sobre Saúde do Trabalhador. Texto Final sobre Saúde do trabalhador. Documento 2. Brasília, DF: Comissão Nacional da Reforma Sanitária; 1987.

15. Brasil. Constituição, 1988. Constituição da República Federativa do Brasil. Brasília, DF: Senado Federal; 1988.

16. Anderson P. Balanço do neoliberalismo. In: Sader E, Gentilli P, organizadores. Pós-neoliberalismo: as políticas sociais e o Estado democrático. São Paulo: Paz e Terra; 1995. p. 9-23.

17. Bresser-Pereira LC. A Reforma administrativa do Sistema de Saúde. Cadernos do Mare da Reforma do Estado. Brasília, DF: Ministério da Administração Federal e Reforma do Estado; 1988.

18. Paula APP. Administração pública brasileira entre o gerencialismo e a gestão social. RAE 2005; 45(1):36-49. 
19. Lacaz A, Goulart P, Junqueira V, organizadores. Trabalhar no Sus: gestão, repercussões psicossociais e política de proteção à saúde. São Paulo: Hucitec; FAPESP; 2017.

20. Antunes R. A nova morfologia da classe trabalhadora no Brasil recente: operariado da indústria, do agronegócio e dos serviços. In: Antunes R. O privilégio da servidão: o novo proletariado de serviços na era digital. São Paulo: Boitempo; 2018. p. 98-133.

21. Goldbaum M. Doença de Chagas e Trabalho em Área Urbana. Saúde debate. 1977; (3): 47-48.

22. Berlinguer G. Saúde não se troca por dinheiro. Saúde debate. 1980; (9):41-46

23. Centro Brasileiro de Estudos de Saúde. Comissão de Saúde Ocupacional do CEBES. Análise crítica do artigo de Laurell: processo de Trabalho e Saúde. Saúde debate. 1981; (11):23-27.

24. Amarante PDC. Trabalho e doença dos trabalhadores. Saúde debate 1981; (11): 23-27.

25. Laurell AC. Processo de Trabalho e Saúde. Saúde debate 1981; (11):8-22

26. Paim JS. A Reforma Sanitária e o Cebes. Rio de Janeiro: Cebes; 2012.

27. Brasil. Ministério da Saúde. A construção do SUS: histórias da Reforma Sanitária e do Processo Participativo. Secretaria de Gestão Estratégica e Participativa. Brasília, DF: Ministério da Saúde, 2006.

28. Escorel S. Reviravolta na saúde: origens e articulações do movimento sanitário. [dissertação]. Rio de Janeiro: Escola Nacional de Saúde Pública Sergio Arouca, Fundação Oswaldo Cruz; 1987.

29. Teixeira SF. O dilema da reforma sanitária. In: Berlinguer G, Campos GWS, Teixeira SF, organizadores. Reforma sanitária Itália e Brasil. São Paulo: Hucitec; Rio de Janeiro: Cebes; 1988. p. 142-167.

30. Sato L, Lacaz FAC, Bernardo MH. Psicologia e Saúde do Trabalhador: práticas e investigações na Saúde Pública de São Paulo. Estudos Psicol. 2006; 11(3):281-288.

31. Tambellini AT. A política de desenvolvimento científico e tecnológico no Brasil na área de saúde e trabalho: discurso e prática. Rio de Janeiro: Abrasco; 1984.

32. Coimbra W, Neves EG. Sobre a Semana de Saúde do Trabalhador (SEMSAT). Saúde debate. 1980; (9):39-40

33. Lacaz FAC. Reforma Sanitária e Saúde do Trabalhador. Saúde soc. 1994; 3(1):41-59.

34. Brasil. Ministério da Saúde. $1^{\text {a }}$ Conferência Nacional de Saúde do Trabalhador. Relatório Final. Brasília, DF: Ministério da Saúde; 1986.

35. Mendes R. Doutrina e prática da integração da saúde ocupacional no setor saúde: contribuição para a definição de uma política. [tese]. São Paulo: Faculdade de Saúde Pública, Universidade de São Paulo; 1986. 384 p.

36. Rêgo MAV. A saúde do trabalhador no âmbito estadual. $1^{\circ}$ Seminário sobre Saúde do Trabalhador. Brasília, DF: Ministério da Saúde; 1993.

37. Mendes R. Subsídios para um debate em torno da revisão do atual modelo de organização da saúde ocupacional no Brasil. Rev. bras. Saúde ocup. 1988; $16(64): 7-25$.

38. Laurell AC, Noriega M. Processo de Produção e Saúde. Trabalho e Desgaste Operário. São Paulo: Hucitec; 1989.

39. Brasil. Ministério da Saúde. Portaria $n^{\circ} 2.728$, de 11 de novembro de 2009. Dispõe sobre a Rede Nacional de Atenção Integral à Saúde do Trabalhador (Renast) e dá outras providências [internet]. Diário Oficial da União. 12 Nov 2009. [acesso em 2020 fev 10]. Disponível em: http://bvsms.saude.gov.br/bvs/saudelegis/ gm/2009/prt2728_11_11_2009.html.

40. Brasil. Decreto n ${ }^{\circ} 7.602$, de 7 de novembro de 2011. Dispõe sobre a Política Nacional de Segurança e Saúde no Trabalho (PNSST). Diário Oficial da União. 8 Nov 2011; 1:9-10. 
41. Brasil. Ministério da Saúde. Portaria ${ }^{0} 1.823$, de 23 de agosto de 2012. Institui a Política Nacional de Saúde do Trabalhador e da Trabalhadora [internet]. Diário Oficial da União. 24 Ago 2012. [acesso em 2020 fev 10]. Disponível em: http://bvsms.saude.gov.br/ bvs/saudelegis/gm/2012/prt1823_23_08_2012.html.

42. Berlinguer G. Medicina e Política. São Paulo: Hucitec; Rio de Janeiro: Cebes; 1978.

43. Navarro V. The Labour Process and Health: a historical materialista interpretation. Inter. J. Health Serv. 1982; 12(1):5-29.

44. Fleury S. Democracia e saúde: algumas considerações políticas. In: Fleury S, organizadora. Saúde coletiva? Questionando a onipotência do social. Rio de Janeiro: Relume-Dumará; 1992. p. 9-11.

45. Fleury TSM. O dilema da reforma sanitária. In: Berlinguer G, Campos GWS, Teixeira SMF. Reforma Sanitária Itália e Brasil. São Paulo: Hucitec; Rio de Janeiro: Cebes; 1988. p. 191-207.

46. Berlinguer G. Uma reforma para a saúde. In: Berlinguer G, Campos GWS, Teixeira SF. Reforma Sanitária Itália e Brasil. São Paulo: Hucitec; Rio de Janeiro: Cebes; 1988. p. 1-106.

47. Berlinguer G. A Saúde nas Fábricas. São Paulo: Hucitec; Rio de Janeiro: Cebes; 1983.

48. Oddone I, Marri G, Briante SGG, et al. A luta contra a nocividade e Reforma Sanitária: uma proposta. In: Oddone I, Marri G, Briante SGG, et al. Ambiente de trabalho: a luta dos trabalhadores pela saúde. São Paulo: Hucitec; 1986. p. 114-133.

49. Singer PI. A crise do "Milagre": interpretação crítica da economia brasileira. Rio de Janeiro: Paz e Terra; 1976.

50. Maeno M, Carmo JC. Saúde do trabalhador no SUS. São Paulo: Hucitec; 2005.

51. Lacaz FAC, Trapé CA, Soares CB, et al. Estratégia saúde da família e saúde do trabalhador: um diálogo possível? Interface. 2013; 17(1):75-87.

52. Cecílio LCO, Chioro RAA. Apontamentos sobre os desafios (ainda) atuais da atenção básica à saúde. Cad. Saúde Pública. 2018; 34(8):1-14.

53. Stotz EM, Cruz Neto O. Processo de trabalho e saúde: o caso dos trabalhadores em curtume. In: Costa NR, Minayo MCS, Ramos CL, et al. Demandas populares, políticas públicas e saúde. Petrópolis: Vozes; Rio de Janeiro: Abrasco; 1989. p. 37-73.

54. Lacaz FAC. O Programa de Saúde do Trabalhador da Secretaria de Estado da Saúde de São Paulo: a agonia de uma proposta. Saúde debate 1992; (36):41-47.

55. Costa NR. Transição e movimentos sociais: contribuição ao debate da Reforma Sanitária. In: Costa NR, Minayo MCS, Ramos CL, et al. organizadores. Demandas populares: políticas públicas e saúde. Petrópolis: Vozes; Rio de janeiro: Abrasco; 1989. p. 45-65.

56. Pimenta A, Capistrano Filho D. Saúde do Trabalhador. São Paulo. Hucitec; 1988.

57. Sindicato dos trabalhadores químicos do ABC. Trabalho, saúde e meio ambiente. Santo André: Sindicato dos Químicos do ABC; 1992.

58. Sader E. Quando novos personagens entram em cena: experiências, falas e lutas dos trabalhadores da Grande São Paulo. Rio de Janeiro: Paz e Terra; 1988.

59. Palma J. Lutas sociais e construção do SUS: o movimento de saúde na zona leste e a conquista da participação popular. São Paulo: Hucitec; Sobravime; 2015.

60. Baudrillard J. À sombra das maiorias silenciosas: o fim do social e o surgimento das massas. São Paulo: Brasiliense; 1993.

61. Minayo-Gomez C. Campo da Saúde do Trabalhador: trajetória, configuração e transformações. In: Minayo-Gomez C, Machado JMH, Pena PGL, organizadores. Saúde do Trabalhador na Sociedade Brasileira Contemporânea. Rio de Janeiro: Fiocruz; 2011. p. 23-34. 
62. Lacaz FAC. Precariedade, intensificação do trabalho e Saúde do Trabalhador: por uma postura anticapitalista das Políticas Sociais. In: Lourenço EAS, organizador. Saúde do Trabalhador e da Trabalhadora e Serviço Social: estudos da relação trabalho e saúde no capitalismo contemporâneo. Campinas: Papel Social; 2016. p. 85-99.

63. Alves G. Reforma trabalhista, modernização catastrófica e a miséria da República brasileira. In: Ramos GT, Melo Filho HC, Loguercio JE, et al. organizadores. O golpe de 2016 e a reforma da previdência: narrativas de resistência. Bauru: Canal 6; 2017. p. 138-145.

64. Fagnani E. Previdência: reformar para destruir? In: Jinkings I, Doria K, Cleto M, organizadores. Por que gritamos golpe?: para entender o impeachment e a crise. São Paulo: Boitempo; 2016. p. 85-89
65. Reis AAC, Soter APM, Furtado LAC, et al. Tudo a temer: financiamento, relação público e privado e o futuro do SUS. Saúde debate. 2016; 40(esp):122-135.

66. Reis AAC. O que será do Brasil e do SUS? Reciis. 2018; 12(2):119-24.

67. Pina JA, Castro HA, Andreazzi MFS. Sindicalismo, SUS e planos de saúde. Ciênc. Saúde Colet. 2006; 11(3):837-846.

Recebido em 30/05/2019

Aprovado em 04/09/2019

Conflito de interesses: inexistente

Suporte financeiro: não houve 